\title{
Fluid reabsorption in the isolated duct of the rat cauda epididymidis
}

\author{
P. Y. D. Wong and C. H. Yeung \\ Department of Physiology, Faculty of Medicine, \\ University of Hong Kong, Hong Kong
}

\begin{abstract}
Summary. A technique is described for measurement of rate of fluid reabsorption in a segment of the rat cauda epididymidis in vitro. The basal rate was $2 \cdot 63 \pm 0 \cdot 22$ $\mu \mathrm{l} / \mathrm{cm}^{2} / 30 \mathrm{~min}$ and was dependent on temperature and inhibited by 2,4-dinitrophenol, suggesting that fluid reabsorption is an energy-dependent process. About $50 \%$ of the fluid reabsorption was dependent on intraluminal sodium ions. This $\mathrm{Na}^{+}$-dependent component was inhibited by addition of amiloride to the intraluminal fluid and ouabain to the peritubular fluid.
\end{abstract}

\section{Introduction}

It is known that the composition of the fluid or plasma which surrounds spermatozoa in the epididymis changes in different regions of the duct and that, as a result, the milieu of spermatozoa in the epididymis differs from that in the testis (Mann, 1959; Scott, Wales, Wallace \& White, 1963; Crabo, 1965; Jones \& Glover, 1973). The acquisition of fertilizing capacity of spermatozoa is lost when the epididymal environment is altered by castration or hypophysectomy (Orgebin-Crist, 1973; OrgebinCrist \& Davis, 1974), and it has been suggested that sperm maturation is dependent on the cumulative action of epididymal secretion. When the spermatozoa pass down the epididymal tract, they encounter a decreasing $\mathrm{Na}^{+} / \mathrm{K}^{+}$ratio and total $\mathrm{Na}^{+}$and $\mathrm{K}^{+}$content (Mann, 1974). Jones \& Glover (1975) found that, in the rabbit, the plasma from the cauda epididymidis contains very little sodium chloride but that the concentration increases after castration; the effect was reversed by treatment with a testosterone implant, suggesting that reabsorption of sodium chloride is under the control of androgen. Levine \& Marsh (1971) measured the transluminal potential in different regions of the rat epididymal tract in vivo and found that in the cauda region the potential was $20.7 \mathrm{mV}$ with the lumen negative with respect to the outside. This potential may be generated as a result of transepithelial sodium transport. Fluid reabsorption takes place along the whole epididymal duct, being about $50 \%$ before the caput epididymidis and a further $25 \%$ of the remaining fluid in the corpus and cauda epididymidis (Crabo \& Gustafsson, 1964; Levine \& Marsh, 1971).

There is a paucity of information on the mechanism of fluid reabsorption in the cauda epididymidis and its dependence on transport of ions across the epithelium. We therefore developed a technique to estimate the rate of fluid reabsorption in the rat cauda epididymidis in vitro.

\section{Materials and Methods}

Male Sprague-Dawley rats weighing between 200 and $300 \mathrm{~g}$ were killed by a blow on the head. The epididymis was quickly removed and placed in cold Kreb's-bicarbonate solution. A segment of the cauda epididymidis (about $0.5 \mathrm{~cm}$ long) was dissected free of fat and connective tissue and placed on a specially designed platform similar to that used for measuring secretory rate in isolated rat seminiferous tubules (Cheung, Hwang \& Wong, 1976). Each end was clamped onto the platform, and incisions were made in the duct close to the clamps. The lumen was then flushed with Kreb's-bicarbonate solution to remove all the spermatozoa. After closing one end with a silk ligature, the tubule was 
filled with about $0 \cdot 25 \mu$ Kreb's-bicarbonate solution, using a polyethylene cannula pulled to a tip diameter of about $150 \mu \mathrm{m}$, and the other end of the segment was also tied. The whole operation was performed under a dissecting microscope at $\times 16$ magnification. The sac of epididymal duct (about $2 \mathrm{~mm}$ long), supported on the platform, was then placed in a small bath (volume $10 \mathrm{ml}$ ) filled with normal Kreb's-bicarbonate solution which was bubbled continuously with $5 \% \mathrm{CO}_{2}$ in $\mathrm{O}_{2}$. The bathing solution was maintained at $35 \pm 0.5^{\circ} \mathrm{C}$ (reabsorptive rate was maximal at $35^{\circ} \mathrm{C}$ ) using a glass heat-exchanger immersed in the bath and the temperature was monitored by a thermistor probe. The peritubular and intraluminal fluids were always iso-osmotic. The Kreb's-bicarbonate solution used had the following composition (mM): $\mathrm{NaCl}, 118 ; \mathrm{KCl}, 4 \cdot 7 ; \mathrm{CaCl}_{2}, 2 \cdot 56 ; \mathrm{MgSO}_{4}, 1 \cdot 13 ; \mathrm{NaH}_{2} \mathrm{PO}_{4}$, $1 \cdot 17 ; \mathrm{NaHCO}_{3}, 25$; glucose, $11 \cdot 1$. When gassed with $5 \% \mathrm{CO}_{2}$ in $\mathrm{O}_{2}$, it had a $\mathrm{pH}$ of $7 \cdot 4$. When sodiumfree solution was used the $\mathrm{NaCl}$ was substituted by an equivalent amount of choline chloride and the $\mathrm{NaHCO}_{3}$ by $\mathrm{KHCO}_{3}(5.9 \mathrm{~mm})$. In this instance, $\mathrm{KCl}$ was omitted and the solution was bubbled with pure $\mathrm{O}_{2}$ to obtain $\mathrm{pH} 7 \cdot 4$.

For estimation of the rate of fluid reabsorption, the bath was examined under $\times \mathbf{4 0}$ magnification and the internal diameter of the lumen was measured at intervals of $0.4 \mathrm{~mm}$ along the length of the sac, using an eyepiece micrometer (Pl. 1, Fig. 1). The mean luminal diameter of the duct was obtained and, by knowing the length of the sac, the luminal volume was calculated. After a 10-min equilibration period, readings of the diameters were taken at 10-min intervals. A reduction in the luminal volume indicated a net reabsorption of fluid in the duct. The rate of fluid reabsorption was expressed in $\mu \mathrm{l}$ fluid reabsorbed $/ \mathrm{cm}^{2}$ of tubule in 10 or $30 \mathrm{~min}$. The reabsorptive area was calculated from the mean internal radius of the tubule and its length $(2 \pi \mathrm{rl})$.

\section{Results}

\section{Basal rate of fluid reabsorption}

The rate of fluid reabsorption was followed over a period of $1 \mathrm{~h}$ (Table 1). The rate decreased with time and at $1 \mathrm{~h}$ was about $30 \%$ less than the initial rate. In subsequent experiments, therefore, the rate of fluid reabsorption was measured over a period of $30 \mathrm{~min}$.

Table 1. Basal rate (mean \pm S.E.M.) of fluid reabsorption $\left(\mu \mathrm{l} / \mathrm{cm}^{2} / 10 \mathrm{~min}\right)$ in the isolated duct of the rat cauda epididymidis (6/group)

\begin{tabular}{lccccccc}
\hline Time (min) & 5 & 15 & 25 & 35 & 45 & 55 & 65 \\
\hline $\begin{array}{l}\text { Fluid } \\
\text { reabsorption }\end{array}$ & $0.79 \pm 0.07$ & $0.79 \pm 0.06$ & $0.70 \pm 0.04$ & $0.65 \pm 0.06$ & $0.62 \pm 0.06$ & $0.57 \pm 0.05$ & $0.52 \pm 0.07$ \\
\hline
\end{tabular}

Table 2. Effect of temperature on the rate (mean \pm S.E.M.) of fluid reabsorption $\left(\mu l / \mathrm{cm}^{2} / 30 \mathrm{~min}\right)$ in the isolated duct of the rat cauda epididymidis

\begin{tabular}{lccccc}
\hline Temperature $\left({ }^{\circ} \mathrm{C}\right)$ & 14 & 22 & 28 & 35 & 40 \\
\hline No. of ducts & 4 & 4 & 4 & 9 & 4 \\
Fluid reabsorption & $0.57 \pm 0.16$ & $1.09 \pm 0.16$ & $1.35 \pm 0.10$ & $1.90 \pm 0.08$ & $1.79 \pm 0.32$ \\
\hline
\end{tabular}

\section{Effect of temperature}

To discover how far fluid reabsorption was dependent on cellular metabolism, the effects of changing the temperature above and below $35^{\circ} \mathrm{C}$ were measured (Table 2). Raising the temperature to $40^{\circ} \mathrm{C}$ had no significant effect on rate of fluid reabsorption, whereas lowering the temperature caused a reduction. From an Arrhenius plot of the data over the range $14-35^{\circ} \mathrm{C}$, it was calculated that the activation energy for the reaction necessary to maintain fluid reabsorption at normal rates is approximately $8.8 \mathrm{kCal} / \mathrm{mol}$. 

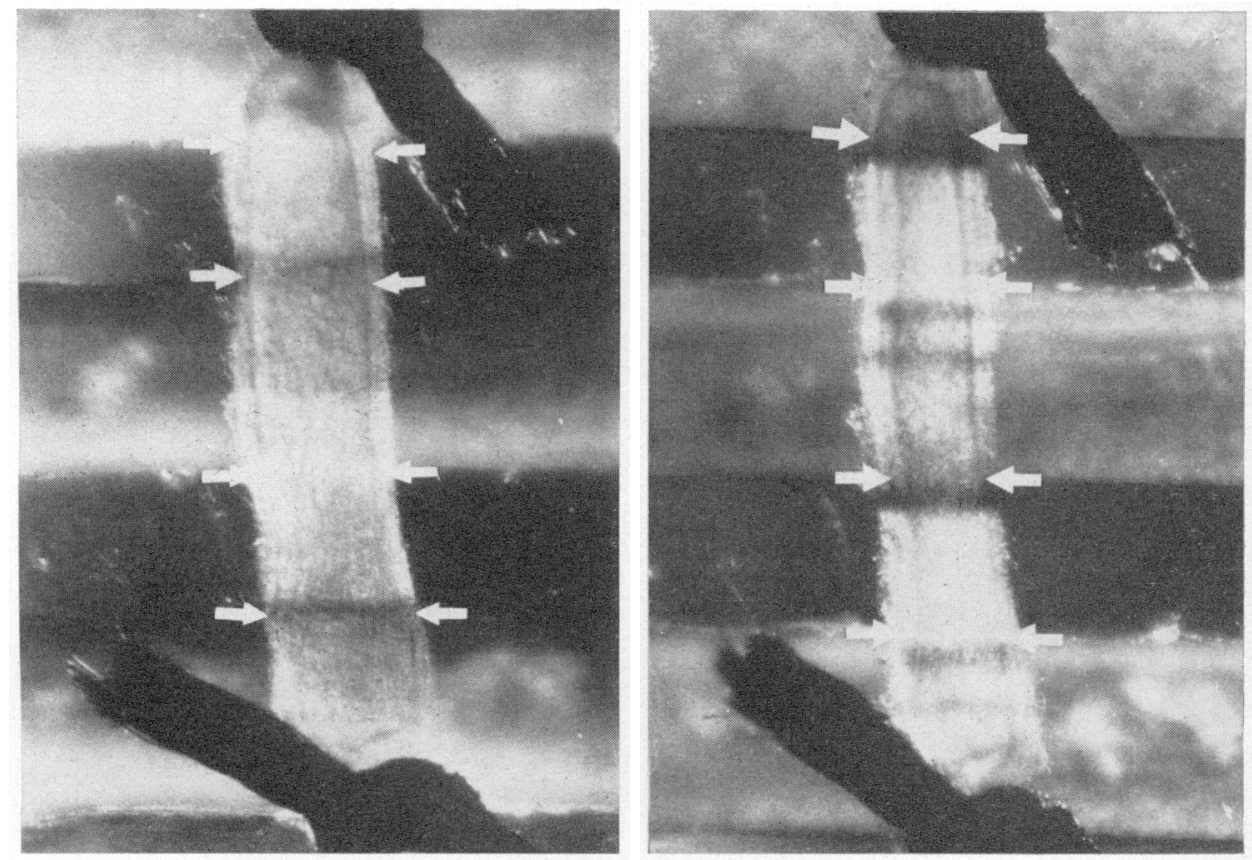

(a)

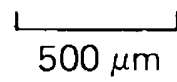

(b)

Photomicrograph $(\times 40$ magnification) in the text. The arrows indicate the places where the diameters of the tubule were taken. The lubule in (b) is the same tubule as that in (a) hut was photographed 40 min latter. 


\section{Effect of 2,4-dinitrophenol}

The effect of this metabolic inhibitor $\left(2.5 \times 10^{-4} \mathrm{M}\right)$ was clear: the control rate was $2.63 \pm 0.22$ (S.E.M.) $\mu$ l fluid $/ \mathrm{cm}^{2} / 30 \mathrm{~min}(n=11)$, and after the inhibitor the rate was $0 \cdot 8 \pm 0.08 \mu 1 \mathrm{fluid} / \mathrm{cm}^{2} / 30$ $\min (n=6)$. The $70 \%$ reduction in fluid reabsorption rate suggests that this is an energy-requiring process.

\section{Dependence on intraluminal $\mathrm{Na}^{+}$and peritubular $\mathrm{K}^{+}$}

The ionic basis of the fluid reabsorption was studied by changing the ionic content of the Kreb'sbicarbonate solution. When the lumen was filled with sodium-free solution, the mean \pm S.E.M. rate of fluid reabsorption was reduced from $2.63 \pm 0.22 \mu \mathrm{l} / \mathrm{cm}^{2} / 30 \mathrm{~min}(n=11)$ to $1.35 \pm 0.22 \mu \mathrm{l}$ / $\mathrm{cm}^{2} / 30 \min (n=6)(P<0.001)$ (Student's $t$ test), indicating that about $50 \%$ of the fluid reabsorption is dependent on the presence of $\mathrm{Na}^{+}$in the intraluminal fluid. When $\mathrm{K}^{+}$was removed from the peritubular fluid, the reabsorption rate was reduced from $2 \cdot 12 \pm 0.09 \mu \mathrm{l} / \mathrm{cm}^{2} / 30 \min (n=11)$ to $1.60 \pm 0 \cdot 19$ $\mu 1 / \mathrm{cm}^{2} / 30 \min (n=5)(P<0.02)$. Therefore, about $50 \%$ of the $\mathrm{Na}^{+}$-dependent reabsorption was inhibited by the removal of $\mathrm{K}^{+}$from the peritubular medium.

\section{Effects of amiloride and ouabain}

When amiloride $\left(10^{-4} \mathrm{M}\right)$, a potent inhibitor of passive $\mathrm{Na}^{+}$transport (see Cuthbert, 1974) was added to the intraluminal fluid, the mean \pm S.E.M. rate of fluid reabsorption was $1.56 \pm 0.13 \mu \mathrm{l} /$ $\mathrm{cm}^{2} / 30 \min (n=6)$. This value was not significantly different from that obtained when the lumen contained $\mathrm{Na}^{+}$-free solution. The addition of amiloride $\left(10^{-4} \mathrm{M}\right)$ to the $\mathrm{Na}^{+}$-free solution, however, had no effect on the rate of fluid reabsorption, which was $1.42 \pm 0.14 \mu \mathrm{l} / \mathrm{cm}^{2} / 30 \mathrm{~min}(n=6)$. Therefore, although the component of fluid reabsorption that is dependent on the intraluminal $\mathrm{Na}^{+}$ can be blocked by amiloride, the component independent of the presence of sodium appeared to be unaffected.

When ouabain $\left(10^{-3} \mathrm{M}\right)$ was added to the peritubular medium, the mean \pm S.E.M. rate of fluid reabsorption was reduced from the control value of $2.63 \pm 0.22 \mu \mathrm{l} / \mathrm{cm}^{2} / 30 \mathrm{~min}(n=6)$ to $1.31 \pm 0.09$ $\mu \mathrm{l} / \mathrm{cm}^{2} / 30 \mathrm{~min}(n=5)(P<0 \cdot 001)$. The addition of ouabain $\left(10^{-3} \mathrm{M}\right)$ to the intraluminal $\mathrm{Na}^{+}-$free solution, however, had no effect on the rate of fluid reabsorption, this value being $1.46 \pm 0.15 \mu \mathrm{g} / \mathrm{cm}^{2} /$ $30 \mathrm{~min}(n=6)$. These results suggest that a $\mathrm{Na}^{+}-\mathrm{K}^{+}$pump is involved in fluid reabsorption in rat cauda epididymidis in vitro.

\section{Discussion}

Although useful in revealing cellular mechanisms in vitro, the results obtained by this technique must be interpreted with caution in relation to fluid reabsorption in the intact epididymis. However, cooling and the metabolic inhibitor 2,4-dinitrophenol inhibited fluid reabsorption in the isolated duct of the rat cauda epididymidis, suggesting that the process is energy-dependent, as is fluid transfer in many mammalian tissues. Fluid secretion in the isolated seminiferous tubules of the rat is also dependent on temperature and supply of substrate and is inhibited by 2,4-dinitrophenol (Cheung et al., 1976).

Because only $50 \%$ of the fluid reabsorption was inhibited when all the sodium ions were removed from the intraluminal fluid, it is possible that part of the fluid reabsorption is secondary to the active transport of sodium. The mechanism for sodium transport may involve a passive diffusion of sodium ions across the luminal membrane and an active extrusion step across the peritubular membrane. Several pieces of evidence suggest that this is true. The decrease in $\mathrm{Na}^{+}$-dependent fluid reabsorption by amiloride is consistent with an inhibition of passive sodium entry at the luminal membrane as observed in isolated rabbit gall bladder (Frederiksen, 1973). Ouabain, an inhibitor of $\mathrm{Na}^{+}-\mathrm{K}^{+}$-activated ATPase, also inhibited the $\mathrm{Na}^{+}$-dependent fluid reabsorption in the segment of 
isolated cauda epididymidis. A similar observation was made by Frederiksen (1972) on transcellular fluid transfer in the rabbit gall bladder in vitro. Removal of peritubular $\mathrm{K}^{+}$ions also caused $50 \%$ inhibition of the $\mathrm{Na}^{+}$-dependent fluid reabsorption in the isolated cauda epididymidis. These findings are consistent with the presence of a $\mathrm{Na}^{+}-\mathrm{K}^{+}$pump in the serosal side of the epithelium (Schmidt \& Dubach, 1971). There is evidence that $\mathrm{Na}^{+}-\mathrm{K}^{+}$-activated ATPase exists in the epididymides of mice (Allen \& Slater, 1959). It is apparent, therefore, that fluid reabsorption is dependent on an active transepithelial transport of sodium from the intraluminal to the peritubular medium, and agrees with the results obtained by Jones (1974) who showed that $\mathrm{NaCl}$ is actively reabsorbed from the rabbit cauda epididymidis in vivo.

The exact mechanism of fluid reabsorption is uncertain. The most attractive model is the standinggradient hypothesis of Diamond \& Tormey (1966), which postulates that solutes are transported actively into intercellular canaliculi making their content hypertonic. The hypertonicity induces a water influx along the canalicular walls which brings the fluid to isotonicity as it flows towards the peritubular phase. Ullrich (1973) considered that fluid transfer may be partly attributed to the hydraulic pressure difference across the epithelium, and in our system it seems possible that the $30 \%$ of the fluid transfer which was insensitive to inhibition by 2,4-dinitrophenol may be associated with the hydraulic pressure difference across the 'leaky' epithelium. However, in some instances, we observed that when the diameter of the epididymal sac was less than the natural diameter of the duct, fluid transfer still took place, presumably in the absence of a hydraulic pressure difference.

In all our experiments, we filled the epididymal sac with fluid of ionic composition similar to that of blood plasma. However, Levine \& Marsh (1971), using a micropuncture technique with rat epididymis in vivo, found that the ionic composition of the epididymal plasma differs considerably from that of blood plasma. The $\mathrm{Na}^{+}$concentration $(20.6 \mathrm{~mm})$ and $\mathrm{Cl}^{-}$concentration $(23.6 \mathrm{~mm})$ were lower, while the $\mathrm{K}^{+}$concentration $(55.1 \mathrm{mM})$ was much higher. This indicates that $\mathrm{Na}^{+}$must be reabsorbed against a high concentration gradient. We are now studying the fluid reabsorption in the isolated duct of the rat epididymis when the intraluminal fiuid is ionically similar to that of epididymal plasma.

We are grateful to Merck, Sharp and Dohm for a supply of amiloride. This work was supported by a World Health Organization Grant to P.Y.D.W.

\section{References}

Allen, J.M. \& Slater, J.J. (1959) A chemical and histochemical study of enzymes dephosphorylating adenosine phosphate esters in epididymis of normal, castrated and testosterone-treated castrated mice. Am. J. Anat. 105, 177-240.

Cheung, Y.M., Hwang, J.C. \& Wong, P.Y.D. (1976) In vitro measurement of the secretory rate in isolated seminiferous tubules of rats. J. Physiol., Lond. 257, $17 P$.

Crabo, B. (1965) Studies on the composition of epididymal content in bulls and boars. Acta vet. scand. 6, Suppl. 5, 1-94.

Crabo, B. \& Gustafsson, B. (1964) Distribution of sodium and potassium and its relation to sperm concentration in the epididymal plasma of the bull. J. Reprod. Fert. 7, 337-345.

Cuthbert, A.W. (1974) Characteristics of sodium channels in transporting epithelia. In Drugs and Transport Processes, pp. 173-184. Ed. B. A. Callingham. Macmillan, London.

Diamond, J.M. \& ToRmey, J. McD. (1966) Studies on the structural basis of water transport across epithelial membranes. Fedn Proc. Fedn Am. Socs exp. Biol. 25, 1458-1463.
Frederiksen, O. (1972) Effect of ethacrynic acid and of ouabain on the transcellular fluid transfer in rabbit gall-bladder in vitro. Proc. 5th Int. Congr. Nephrol., Mexico, Abstr. 762.

Frederiksen, O. (1973) Effect of amiloride on the transepithelial fluid transfer mechanism in rabbit gallbladder in vitro. Acta physiol. scand., Suppl. 396.

JONES, R. (1974) Absorption and secretion in the cauda epididymidis of the rabbit and the effects of degenerating spermatozoa on epididymal plasma after castration. J. Endocr. 63, 157-165.

JONES, R. \& Glover, T.D. (1973) The collection and composition of epididymal plasma in the rabbit. J. Reprod. Fert. 34, 395-403.

JONEs, R. \& Glover, T.D. (1975) Interrelationship between spermatozoa, the epididymis and epididymal plasma. In The Biology of the Male Gamete, pp. 367-384. Eds J. C. Duckett \& P. A. Racey. Academic Press, London.

LEVINE, N. \& MARSH, D.J. (1971) Micropuncture studies of the electrochemical aspects of fluid and electrolyte transport in individual seminiferous tubules, the epididymis and the vas deferens in rats. $J$. Physiol., Lond. 213, 557-570. 
MANN, T. (1959) Biochemistry of semen and secretions of male accessory organs. In Reproduction in Domestic Animals, Vol. II, pp. 51-73. Eds H. H. Cole \& P. T. Cupps. Academic Press, New York.

MANN, T. (1974) Biochemical aspects of sperm maturation. In Male Fertility and Sterility, pp. 89-105. Eds R. E. Mancini \& L. Martini. Academic Press, New York.

ORGebn-Crist, M.-C. (1973) Maturation of spermatozoa in the rabbit epididymis: effect of castration and testosterone replacement. J. exp. Zool. 185, 301-307.

Orgebin-Crist, M.C. \& Davis, J. (1974) Functional and morphological effect of hypophysectomy and androgen replacement in the rabbit epididymis. Cell Tiss. Res. 148, 183-201.
ScHMDT, U. \& DUBACH, U.C. (1971) Na-K stimulated adenotriphosphatase: intracellular localization within the proximal tubule of the rat nephron. Pfügers Arch. ges. Physiol. 330, 265-270.

ScotT, T.W., Wales, R.G., Wallace, J.C. \& White, I.G. (1963) Composition of ram epididymal and testicular fluid and the biosynthesis of glycerylphosphorylcholine by the rabbit epididymis. $J$. Reprod. Fert. 6, 49-59.

UllrICH, K.J. (1973) Permeability characteristics of the mammalian nephron. In Handbook of Physiology, Section 8, Ch. 12, Renal Physiology, pp. 377-398. Eds J. Orloff \& R. W. Berliner. American Physiological Society, Washington D.C.

Received 21 Jume 1976 